\title{
REVIEW OF «WHY WE CANNOT PREDICT STRONG EARTHQUAKES IN THE EARTH'S CRUST» BY I.L. GUFELD, M.I. MATVEEVA AND O.N. NOVOSELOV
}

\author{
A. V. Nikolaev \\ Schmidt Institute of Physics of the Earth RAS, 123995, Moscow, Bolshaya Gruzinskaya street, 10-1, Russia
}

\begin{abstract}
In the review, directions of future studies of the seismic process are considered. The priority shall be given to studies of the barrier effect of degassing and research of processes that take place in marginal structures. A scenario of preparation of the seismic process and associated events is described with regard to uncertainties in development of critical seismotectonic situations.
\end{abstract}

Key words: seismic process, prediction/forecast of earthquakes, Earth degassing.

Citation: Nikolaev A.V. Review of «Why we cannot predict strong earthquakes in the Earth's crust» by I.L. Gufeld, M.I. Matveeva, and O.N. Novoselov // Geodynamics \& Tectonophysics. 2011. V. 2. № 4. P. 416417. doi:10.5800/GT-2011-2-4-0052.

\section{РЕЦЕНЗИЯ НА СТАТЬЮ И.Л. ГУФЕЛЬДА, М.И. МАТВЕЕВОЙ И О.Н. НОВОСЕЛОВА «ПОЧЕМУ МЫ НЕ МОЖЕМ ОСУЩЕСТВИТЬ ПРОГНОЗ СИЛЬНЫХ КОРОВЫХ ЗЕМЛЕТРЯСЕНИЙ»}

\author{
А. В. Николаев \\ Институт физики Земли им. О.Ю. Шмидта РАН, 123995, Москва, ГСП-5, \\ ул. Большая Грузинская, 10, стр. 1, Россия
}

\begin{abstract}
Аннотация: В отзыве рассматриваются направления дальнейших исследований сейсмического процесса, в которых на первый план выдвигаются работы по изучению барьерного эффекта дегазации, а также процессов в граничных структурах. Представлен сценарий подготовки сейсмического процесса и сопутствующих явлений с учетом неопределенности развития критических сейсмотектонических ситуаций.
\end{abstract}

Ключевые слова: сейсмический процесс, прогноз землетрясений, дегазация Земли.

Проблемы прогноза землетрясений не просто актуальны. Они требуют решений. Особенно, после того, как традиционные сейсмология и геофизика, по существу, пропустили катастрофическое землетрясение в Японии, хотя непрерывный и долговременный мони- торинг сейсмоактивной зоны осуществляется на расстоянии всего лишь 200 км. Очевидно, что мы ведем мониторинг не тех параметров, или неправильно, или не можем их интерпретировать. И вообще вопрос, что мы контролируем. На эти вопросы сейчас надо отве- 
чать. Одной из главных причин неудач являются традиционные представления о геологической среде как линейной, пассивной и с неизменными во времени параметрами. В рамках линейных моделей путем их усложнения многое можно было пытаться объяснить, но еще больше проблем и фактов оставались открытыми, да и к проблеме прогноза мы не приближались, так как выделить реальные предвестники не удалось.

Авторы представили обзор на основе нетрадиционных взглядов на сейсмический процесс, однако учитывая хорошо известные данные и факты, а также реальные процессы в литосфере, которые ранее не рассматривались. При этом модели сейсмического процесса предложены для реальной геологической среды, отличающейся предельной энергонасыщенностью, неоднородностью, собственной внутренней активностью и непрерывным изменением параметров на различных масштабных уровнях (т.е. нестабильность среды, ее «мутность»), а также особенностями взаимодействия различных физических полей, контролирующих реальную нелинейность процессов в среде. В этом плане авторами реализуется продолжение идей М.А. Садовского. Однако были и другие особенности геологической среды, которые не учитывались в линейных моделях. Это особенности деструкции среды, обусловленные P-T параметрами и взаимодействием восходящих потоков легких газов с твердой фазой. Именно дегазация легких газов контролирует непрерывную изменчивость параметров среды. Это идеи авторов, которые развиваются ими в последние 15 лет.

В работе показано, что дегазация Земли и разгрузка среды природными газами являются тем связующим звеном, который позволяет с одних позиций подойти к объяснению процессов подготовки очагов землетрясений в различных зонах, природы микросейсмического шума, колебательного режима объемно-напряженного состояния блоковых структур, природы наиболее сильных триггерных эффектов, деструкции земной коры, расслоенности слабо нагруженного поверхностного слоя коры. Затрагивается весьма важный вопрос, касающийся процессов в граничных структурах блоков, самой структуры граничных слоев и устойчивости этих структур. С учетом реальных свойств литосферы, прежде всего ее нестабильности, и процессов, протекающих в ней, обсуждаются модели подготовки очагов сильных землетрясений для платформенных зон и зон субдукции.

На этой основе анализируются причины наших неудач в прогнозе сейсмической опасности. Предвестники землетрясений искали в разрушенном поверхностном слое, не терпящем перенапряжений. Показано, что наблюдаемые аномалии различных полей не являются предвестниками конкретных землетрясений, а отражают совсем другие процессы. Особенно показателен такой провал при анализе процессов перед Японским событием 11.03.2011 г. Методология современного прогноза, основанная на представлениях механики разрушения однородных материалов, обладающих линейными и нелинейными свойствами, теряет смысл.

В статье рассматриваются направления дальнейших исследований сейсмического процесса, при этом на первый план выдвигаются работы по изучению барьерного эффекта дегазации, процессов разгрузки среды природными газами, процессов в граничных структурах. Обсуждаются направления работ по методам мониторинга сейсмической опасности для реальных геологических сред.

В отличие от предыдущих обзоров, в работе представлен сценарий развития сейсмического процесса и сопутствующих явлений с учетом неопределенности развития критических сейсмотектонических ситуаций. Именно поэтому обзор представляет большой интерес для специалистов.

Рекомендую работу для раздела дискуссии в том виде, в котором она представлена. Конечно, у рецензентов и специалистов могут быть замечания и другие взгляды. Но я глубоко убежден, что сейчас эти замечания должны быть публичными, лично представленными в печати каждым из них. Причем все должны быть готовыми не только критиковать, но и излагать свои взгляды на сейсмический процесс и проблему прогноза с учетом реалий литосферы и всеобщего негативного опыта прогноза.

Вопрос, что дальше делать? Авторы изложили свои взгляды.

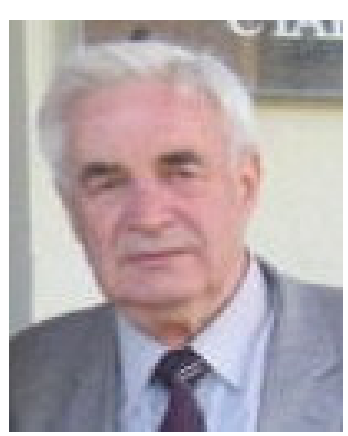

Николаев Алексей Всеволодович, докт. физ.-мат. наук, профессор, чл.-корр. РАН

Председатель Российского экспертного совета по прогнозу землетрясений и оценке сейсмической опасности зав. лабораторией экспериментальной геофизики

Институт физики Земли им. О.Ю. Шмидта РАН

123995, Москва, ГСП-5, ул. Большая Грузинская, 10-1, Россия

$\triangle$ e-mail: nikavs@ifz.ru

Nikolaev, Alexey V., Doctor of Physics and Mathematics, Corresponding Member of RAS

Chairman of the Russian Expert Council for Earthquake Prediction and Seismic Hazard Assessment

Head of Laboratory of Experimental Geophysics

The Schmidt Institute of Physics of the Earth RAS

123995, Moscow, GSP-5, Bolshaya Gruzinskaya street, 10-1, Russia

$\triangle$ e-mail: nikavs@ifz.ru 